\title{
Controle de vida, interseccionalidade e politica de empoderamento: as organizações políticas das trabalhadoras domésticas no Brasil
}

\author{
Life control, interseccionality and politics \\ of empowerment: female domestic \\ workers' political organizations in Brazil \\ Joaze Bernardino Costa
}

\section{Introdução}

O serviço doméstico no Brasil, em 2009, empregava 7,2 milhões de pessoas, das quais $93 \%$ eram mulheres. Destas, $61,6 \%$ eram negras e $38,4 \%$ brancas. A sobrerrepresentação de trabalhadoras domésticas negras se torna mais evidente quando percebemos que, para cada 100 mulheres brancas ocupadas, 12 são trabalhadoras domésticas, enquanto para cada 100 mulheres negras o número sobe para 21. Essa ocupação profissional tem sido marcada pela desproteção legal e

Joaze Bernardino Costa é doutor em Sociologia pela Universidade de Brasília e professor adjunto da Universidade de Brasília (joazebernardino@uol.com.br).

Artigo recebido em 27 de junho e aprovado para publicação em 10 de setembro de 2013.

Est. Hist., Rio de Faneiro, vol. 26, no 52, p. 471-489, julho-dezembro de 2013. 


\section{Joaze Bernardino Costa}

pela precariedade das condições de trabalho, como bem têm assinalado diversos estudos (Pinheiro, Fontoura e Pedrosa, 2011; Kofes, 2001; Brites, 2000; Ávila, 2009). Se essa tem sido a tônica em torno do trabalho doméstico, isso não quer dizer que não haja esforços de movimentos sociais, especialmente das próprias trabalhadoras domésticas, para reverter esse quadro.

A ampliação do direito das trabalhadoras domésticas está na ordem do dia em virtude da recém-aprovada Emenda Constitucional 72, que estabelece a equiparação legal entre trabalhadoras domésticas e demais trabalhadores urbanos e rurais do país. A conquista desses direitos está diretamente ligada à organização política das trabalhadoras domésticas, movimento que data da década de 30 do século passado. A aprovação da Emenda Constitucional 72 não foi fruto do acaso, e sim de um longo processo histórico, em que a organização política das trabalhadoras domésticas, articulada com outros movimentos sociais, obteve êxito nas suas reivindicações. É óbvio que esse avanço legal pode não significar muito, pode inclusive se converter em "letra morta", haja vista que, por exemplo, 3/4 das trabalhadoras domésticas não dispõem da carteira de trabalho assinada, um direito garantido desde 1972. Portanto, se a lei vai "pegar" ou não, depende de inúmeras variáveis, que não serão objeto de estudo neste artigo.

O que este artigo se propõe é reconhecer e registrar o papel desempenhado pelas organizações políticas das trabalhadoras domésticas - suas associações e sindicatos - ao longo dos últimos quase 80 anos. Nesse período, constatamos um esforço das trabalhadoras domésticas para assumir o controle de suas vidas a partir de suas reivindicações trabalhistas. Nesse processo, as diversas organizações estabeleceram articulações com outros movimentos, classistas-sindicais, feministas e antirracistas, em escala nacional e, mais recentemente, em escala internacional.

Reescrever a história dos avanços legais das trabalhadoras domésticas, destacando a importância dessas mulheres no fazer histórico, significa, por um lado, questionar um tipo de narrativa que desqualifica suas vozes e, por outro, pensar o processo histórico a partir também do ponto de vista dos atores e atrizes subalternos, tal como tem feito o prestigioso grupo de estudos da subalternidade situado no sudeste asiático (Guha, 1997; Rivera Cusicanqui y Barragán, 1997).

Este artigo, motivado pelas recentes discussões sobre trabalho doméstico no Brasil, baseia-se em duas pesquisas anteriores, oportunidades em que pude realizar entrevistas com diversas lideranças dos sindicatos de trabalhadoras domésticas de São Paulo, Campinas, Franca, Rio de Janeiro, Nova Iguaçu, Recife e Salvador, e com a presidente da Federação Nacional das Trabalhadoras Domésticas. Nessas pesquisas procurei registrar a história das trabalhadoras domésticas - especialmente sua luta pela conquista de direitos - a partir de seu próprio pon- 


\section{Controle de vida, interseccionalidade e política de empoderamento}

to de vista. Para tanto, não somente baseei-me no depoimento oral de 31 trabalhadoras domésticas, mas também procurei recuperar as resoluções dos dez congressos nacionais já organizados por essa categoria profissional (cf. Bernardino-Costa, 2007 e 2011).

Conforme argumentaremos nas páginas que seguem, a história dessas trabalhadoras, antes de ser uma história de vítimas, revela o protagonismo de mulheres negras e seus esforços para o controle de suas vidas e seus destinos.

\section{Controle da vida e da imagem, interseccionalidade e política de empoderamento}

Um tema central para a população negra da diáspora é como retomar o controle de suas vidas e suas imagens dentro das sociedades hegemônicas. $\mathrm{O}$ não controle da vida e da imagem condenou a população negra a papéis subalternos, assim como produziu imagens distorcidas dessas populações no interior das sociedades nacionais. Tanto a posição na estrutura sócio-ocupacional quanto preconceitos geram um círculo vicioso que fortalece as relações de subalternização.

A necessidade de retomada do controle da imagem e da vida é evidentemente um tema central para as mulheres negras. Tema comum nas duas maiores sociedades ocidentais que tiveram a experiência da escravidão - Brasil e Estados Unidos - é a associação da imagem das mulheres negras aos papéis sócio-ocupacionais de trabalhadoras domésticas. Mesmo que atualmente nos Estados Unidos o trabalho doméstico remunerado esteja sendo realizado em sua maior parte por mulheres latinas, persiste no imaginário social a associação da mulher afro-americana com o trabalho doméstico (Hooks, 1995). No caso da sociedade brasileira, há não só a associação da mulher negra ao trabalho doméstico, como há também sua associação à condição de objeto sexual, tão celebrada nacional e internacionalmente no Carnaval (Gonzales, 1984; Giacomini, 2006).

Esse aprisionamento da mulher negra a determinados papéis constitui um desafio ao movimento das mulheres negras no Brasil. Parte da estratégia para retomar esse controle em suas mãos é o desenvolvimento de um pensamento feminista negro, em que as atrizes sociais se tornem protagonistas de suas histórias, bem como das narrativas de suas histórias.

No caso das trabalhadoras domésticas no Brasil, essa luta pelo controle da vida e da imagem se dá através da luta e do ativismo coletivo da categoria profissional, o que remete à década de 1930. Ao longo de quase 80 anos de ativismo, encontramos uma articulação política com outros atores sociais, mais especificamente com os movimentos classistas, feministas e negro, como demonstraremos logo abaixo. 


\section{Joaze Bernardino Costa}

A articulação política com os movimentos classistas, feministas e negro pode ser melhor compreendida a partir da noção de interseccionalidade. Tal noção remete a duas dimensões: desempoderamento e empoderamento. Enquanto conceito utilizado para pensar o desempoderamento, a interseccionalidade se refere à maneira pela qual o racismo, as relações patriarcais, a opressão de classe e outros eixos possíveis de poder e discriminação criam desigualdades. Esse conceito ganhou notoriedade na década de 1990, a partir das formulações de Patricia Hill Collins (2000) e Kimberle Crenshaw (2002) em suas críticas ao feminismo hegemônico nas sociedades ocidentais modernas, especialmente nos Estados Unidos, em que se supunha que a dimensão de gênero explicava plenamente a realidade de todas as mulheres. Crenshaw, por exemplo, a partir de uma metáfora de encontro de avenidas, explica o sentido do conceito de interseccionalidade. Diz ela:

as mulheres racializadas frequentemente estão posicionadas em um espaço onde o racismo ou a xenofobia, a classe e o gênero se encontram. Por consequência, estão sujeitas a serem atingidas pelo intenso fluxo de tráfego em todas estas vias (Crenshaw, 2002: 177).

O indivíduo sujeito à interseccionalidade, nas descrições da autora, torna-se equivalente a um "pedestre" no encontro dessas várias avenidas, sofrendo os danos causados por impactos vindos de diferentes direções. Nesse sentido, os eixos de poder de classe, raça, gênero, sexualidade atuam de maneira dinâmica, desempoderando os atores e atrizes sociais que eventualmente possam estar situados no encontro desses eixos. Assim como a metáfora do encontro de avenidas remete a forças dinâmicas e em movimento provenientes de diversas direções, o conceito de interseccionalidade também remete a um caráter dinâmico da discriminação e desempoderamento provocados por diversos eixos de poder.

Todavia, o conceito de interseccionalidade não remete somente às dimensões de opressão, desigualdade e discriminação. Embora não seja enfatizado na mesma intensidade, ele remete também às relações de empoderamento. Crenshaw observa que as dinâmicas dos eixos de poder - raça, classe, gênero, sexualidade, nacionalidade etc. - não são unilaterais no sentido de gerar somente opressão, uma vez que os membros dos grupos marginalizados são capazes de resistir e gerar mobilizações políticas individuais e/ou coletivas. Essa abordagem da interseccionalidade também é compartilhada por Patricia Hill Collins, que supõe uma dialética entre opressão e ativismo (Collins, 2000: 13).

Outra autora que apresenta significativas contribuições à discussão do conceito de interseccionalidade é Avtar Brah (1996 e 2006). Embora não deixe de 
chamar a atenção para a dimensão opressiva, discriminatória e exploratória das relações de poder, Brah destaca também a dimensão de ativismo e mobilização política trazida por esse conceito. Dependendo do contexto histórico, os marcadores de diferença que informam a noção de interseccionalidade podem conduzir a formas democráticas de agenciamento político (Brah, 2006: 16).

Se classe, raça e gênero são considerados eixos de poder, é oportuno trazer à lembrança as considerações foucaultianas a respeito do poder. Poder não é uma propriedade, mas uma relação. As relações de poder se alteram constantemente, surgindo novos conflitos e novos pontos de resistência, consequentemente produzindo novos sujeitos (Foucault, 1995). Assim, dependendo do contexto, a noção de interseccionalidade pode ser utilizada não somente para analisar efeitos negativos, tais como opressão e desempoderamento, mas para analisar a mobilização política.

O conceito de interseccionalidade se apresenta como um conceito profícuo, uma vez que nos permite visualizar duas dimensões das relações de poder: por um lado, a produção de desempoderamento, opressão, discriminação; por outro, a produção de agências políticas, mobilizações democráticas e sujeitos políticos.

Além disso, a utilização desse conceito nos permite um padrão de análise baseado na interação de uma multiplicidade de eixos de diferenciação e poder. Esse conceito enfatiza que diferentes dimensões da vida social não podem ser separadas para oferecer explicações absolutas sobre os processos de poder e desigualdades. Ao contrário, chama nossa atenção para uma análise que articula os vários sistemas de diferenciação existentes nos específicos contextos locais.

Esse conceito se torna uma importante ferramenta para compreender como são produzidas e mantidas a discriminação, opressão e dominação das trabalhadoras domésticas no Brasil, bem como para compreender a mobilização política dessas trabalhadoras. Exploraremos, a seguir, como esse conceito nos permite compreender o fortalecimento político das trabalhadoras domésticas no Brasil.

\section{Interseccionalidade e empoderamento: organizações políticas das trabalhadoras domésticas no Brasil}

Constitui um divisor de águas para as trabalhadoras domésticas participar das atividades políticas nos sindicatos da categoria profissional. Os sindicatos são espaços de ruptura com o isolamento intramuros vivenciado pelas trabalhadoras, bem como com as relações tipicamente hierarquizadas vividas no interior da casa da patroa. Atualmente existem cerca de 133 mil trabalhadoras orga- 


\section{Joaze Bernardino Costa}

nizadas em sindicatos, o que corresponde a quase $2 \%$ do total de trabalhadoras domésticas. Dessas trabalhadoras filiadas a sindicatos $61,1 \%$ são negras (cf. Pinheiro, Fontoura e Pedrosa, 2011).

A seguir, abordaremos de maneira pormenorizada o movimento das trabalhadoras domésticas no Brasil desde o seu nascedouro na década de 1930 até os dias atuais. Para tanto, basearemos nossa análise naqueles sindicatos considerados estruturais para o movimento das trabalhadoras domésticas: ${ }^{1}$ (a) o Sindicato de Campinas, (b) o Sindicato de São Paulo, (c) o Sindicato do Rio de Janeiro, (d) o Sindicato da Bahia e (e) o Sindicato de Recife. Também fundamentaremos nossas interpretações em pesquisa realizada junto à Federação Nacional dos Trabalhadores Domésticos, a Fenatrad. Além disso, tivemos acesso às resoluções dos congressos nacionais organizados pela categoria. ${ }^{2}$ Ao longo dessas quase oito décadas de organização, o que tem sido constatado é uma articulação da atividade política em torno das interpretações de classe, de gênero e de raça.

O movimento das trabalhadoras domésticas teve início em 1936, através da atuação de Laudelina de Campos Melo, quando esta fundou a Associação Profissional dos Empregados Domésticos de Santos. ${ }^{3}$ Explicitamente, essa pioneira organização das trabalhadoras domésticas tinha o objetivo de conquistar o status jurídico de sindicato, uma vez que este poderia negociar com o Estado o reconhecimento jurídico da categoria e, consequentemente, os direitos trabalhistas. A exclusão das trabalhadoras domésticas naquele momento não se restringia somente ao não direito à sindicalização, mas envolvia também a não regulamentação da profissão, o que seria confirmado pela Consolidação das Leis do Trabalho, de $1943 .^{4}$

Se a exclusão dos direitos trabalhistas foi o motivador da primeira organização política das trabalhadoras domésticas no país, não devemos interpretar como simples coincidência o fato de a associação ter sido fundada por uma militante do movimento negro da época. Laudelina de Campos Melo (1904-1991) já militava em organizações negras desde 1920, em Poços de Caldas (MG), em Santos (SP) e na capital paulista. Na década de 1930, Laudelina tinha contato com militantes de associações negras de São Paulo, sendo inclusive uma militante da Frente Negra Brasileira (cf. Pinto, 1993).

A partir da década de 1960, houve um segundo momento de crescimento e fortalecimento do movimento das trabalhadoras domésticas. A década foi precedida por discussões sobre a situação da trabalhadora doméstica na sociedade brasileira feitas especialmente por organizações do movimento negro. A título de exemplo, o Teatro Experimental do Negro (TEN) tinha entre seus quadros Arinda Serafim, uma trabalhadora doméstica que mobilizou suas companheiras para as aulas de alfabetização do TEN e as envolveu nos estudos dos direitos das trabalhadoras domésticas (cf. Sermog \& Nascimento, 2006). Além disso, perce- 


\section{Controle de vida, interseccionalidade e política de empoderamento}

bemos também, em 1950, o acompanhamento das discussões do projeto de lei do então deputado Café Filho, que visava regulamentar a profissão e garantir os primeiros direitos positivos às trabalhadoras domésticas, no jornal $O$ Quilombo: vida, problemas e aspirações do negro, editado e dirigido por Abdias Nascimento (cf. Nascimento, 2003: 79).

Indubitavelmente importante para o novo fôlego do movimento das trabalhadoras domésticas na década de 1960 foi a atuação da Igreja católica através da Juventude Operária Católica (JOC). ${ }^{5}$ Em 1960, a JOC realizou o Primeiro Encontro Nacional de Jovens Empregadas Domésticas no Rio de Janeiro, que reuniu 24 trabalhadoras domésticas de várias regiões do país. No ano seguinte a JOC também realizou o Primeiro Congresso Regional, em Recife, reunindo trabalhadoras do Ceará, Rio Grande do Norte, Paraíba e Pernambuco (cf. Soares, 2002).

É importante mencionar que a JOC era uma organização voltada para os trabalhadores em sua acepção universal. Porém as trabalhadoras domésticas estavam deslocadas nas reuniões da JOC devido à peculiaridade da sua situação frente aos demais trabalhadores, que já estavam enquadrados nas leis trabalhistas do país, enquanto elas ainda estavam lutando pelas primeiras regulamentações. Devido a esse fato foram formados grupos específicos de trabalhadoras domésticas ligados à JOC. Odete Maria Conceição, uma das fundadoras da Associação Profissional dos Empregados Domésticos do Rio de Janeiro, menciona essa incompatibilidade entre o movimento operário em geral e o movimento das trabalhadoras domésticas:

uma vez por mês a gente (os diversos grupos de trabalhadoras domésticas em diferentes paróquias do Rio de Janeiro) se reunia todo mundo junto, e daí a gente foi vendo a diferença que havia entre nós e os outros trabalhadores, que os outros tinham seus direitos, e a doméstica não tinha nada. Então foi daí que a gente foi vendo a necessidade da gente ter alguma coisa pra defender a gente. ${ }^{6}$

Entre as associações e grupos de trabalhadoras domésticas que surgiram na década de 1960 como uma decorrência do trabalho da JOC, podemos mencionar as associações ou grupos de Recife, Rio de Janeiro, Belo Horizonte, São Paulo, Piracicaba, Porto Alegre, entre outras.

Ao mesmo tempo em que surgiam associações e grupos a partir da JOC porém não subordinados à Igreja católica -, Laudelina de Campos Melo atuava, desde 1959, em Campinas para a fundação da Associação dos Empregados Domésticos local. Em lugar de um papel predominante da Igreja católica, encontra- 


\section{Joaze Bernardino Costa}

mos em Campinas uma articulação com o movimento negro, especialmente o Teatro Experimental do Negro, e com o movimento sindicalista.

Assim, na década de 1960, o movimento das trabalhadoras domésticas ganhou uma dimensão nacional, sendo fruto da interação da JOC, do movimento negro e do movimento sindical. Obviamente as contribuições dessas organizações se apresentaram de maneira diferenciada em cada associação e grupo. De toda forma, sua interação permitiu o surgimento de um movimento das trabalhadoras domésticas em todo o território nacional. Se em 1960 o $1{ }^{\circ}$ Encontro Nacional das Jovens Trabalhadoras Domésticas, no Rio de Janeiro, ainda foi realizado sob os auspícios da JOC, o $1^{\circ}$ Congresso Nacional das Trabalhadoras Domésticas, realizado em São Paulo em 1968, foi fruto de sua ação autônoma. Isso, todavia, não significou que as trabalhadoras domésticas não tivessem recebido apoio da Igreja católica.

A relação das organizações políticas com a Igreja católica permaneceu ambígua até finais da década de 1970. Embora a ala progressista da Igreja tenha se posicionado como apoiadora das trabalhadoras domésticas, reconhecendo seu protagonismo, outros setores defendiam uma concepção religiosa da trabalhadora doméstica associada ao mito de Santa Zita, ${ }^{7}$ utilizado para enfatizar que a função da trabalhadora doméstica consistia em servir a família para a qual ela trabalhava.

A ruptura das organizações políticas das trabalhadoras domésticas com o mito de Santa Zita ocorreu no $3^{\circ}$ Congresso Nacional das Trabalhadoras Domésticas, em 1978, em Belo Horizonte, quando o arcebispo daquela cidade e algumas patroas tentaram monopolizar os espaços de fala, enfatizando o papel servil das trabalhadoras domésticas, sem reconhecê-las como trabalhadoras e consequentemente portadoras de direito. Naquele congresso, Lenira Carvalho, uma das principais lideranças do movimento à época, foi chamada para compor a mesa de encerramento. Então, na sua fala, ela rompeu com a ideia de subserviência das trabalhadoras domésticas, associada ao mito de Santa Zita, e enfatizou a necessidade de elas serem reconhecidas em seus direitos. Vejamos sua narrativa:

O Congresso de Belo Horizonte foi dominado por patroas, dominado mesmo. E tinha um padre lá, que ele fez uma divulgação, que eu acho que nunca teve um Congresso que teve tanta gente no encerramento. Agora no decorrer do Congresso, teve uma vez que pediram pra mim: "Lenira, vê se você vai lá em cima e dá uma virada nesse congresso." Teve uma briga no auditório com a televisão, com tudo, porque uma mulher que não era nem empregada doméstica queria dominar, queria falar. Então foi muito negativo por isso. Então o ministro do 


\section{Controle de vida, interseccionalidade e política de empoderamento}

Trabalho veio. Eu não fui nem pra receber o ministro. Equiseram que eu fosse entregar umas coisas de flores pra o ministro, queriam que eu falasse... Aí me escolheram pra eu falar no encerramento. Aí no encerramento eu dei a virada só na falação, falei que o que precisava era reconhecer os direitos das trabalhadoras domésticas. Aí teve empregada que chorou, tinha uma que vinha falar comigo chorando... (Entrevista Lenira de Carvalho, membro fundadora do Sindicato de Recife)

Durante essa fase do movimento, em sua dimensão nacional, predominou a interpretação classista da condição da trabalhadora doméstica. ${ }^{8}$ Tanto nas organizações do Rio de Janeiro quanto do Recife, estudadas por nós, percebe-se a predominância desse discurso. Cabe destacar que a própria interpretação da JOC também era uma interpretação classista. O que se formulou nessa ocasião até meados da década de 1980 foi uma compreensão da luta da trabalhadora doméstica predominantemente como uma luta de classes, como revela o depoimento de Lenira Carvalho.

É essa compreensão que se tem também do movimento nacional, quando se observam as resoluções dos congressos nacionais. Não se trata de dizer que as interpretações baseadas em raça e gênero não estavam presentes, mas de perceber que a articulação política se dava em torno da demanda das trabalhadoras domésticas de serem reconhecidas como pertencentes à classe trabalhadora e, consequentemente, equiparadas em termos de direitos aos outros trabalhadores. Essa era uma consequência natural do fato de as trabalhadoras domésticas somente terem sido reconhecidas pela legislação trabalhista em 1972, ainda de maneira extremamente restritiva, já que conquistaram na ocasião apenas o direito à carteira de trabalho, a férias e à previdência social. Nesse sentido, a luta incidia sobre a efetivação desses poucos direitos e sobre a conquista de outros já compartilhados por outras categorias.

As campanhas desenvolvidas durante esse período - inícios da década de 1960 a meados da década de 1980 - tinham como foco o reconhecimento classista-profissional das trabalhadoras domésticas, e diversas associações lançaram-se à campanha para a trabalhadora morar na sua própria casa e romper com a concepção de membro da família.

$\mathrm{E}$ interessante observar que mesmo sendo o discurso classista o carro-chefe da campanha pela moradia, categorias colonial-raciais estavam presentes. Em diversas entrevistas realizadas e na documentação a que tivemos acesso, frequentemente verificamos a identificação do quarto de empregada com a senzala, da casa da patroa/patrão com a casa grande e do trabalho doméstico com o trabalho escravo. 


\section{Joaze Bernardino Costa}

Entretanto, não há dúvida de que no horizonte das trabalhadoras domésticas estava o reconhecimento profissional, dependente, por sua vez, de seu reconhecimento como integrantes da classe trabalhadora.

O relacionamento com as entidades políticas da classe trabalhadora foi marcado por idas e vindas ao longo do tempo, possuindo também sua variação regional. Em algumas cidades os sindicatos da classe trabalhadora foram efetivos parceiros dos sindicatos das trabalhadoras domésticas, enquanto em outras localidades houve atritos e desconfianças.

$\mathrm{O}$ mesmo aconteceu com o movimento feminista. O relacionamento das trabalhadoras domésticas com o movimento feminista iniciou-se com enormes desconfianças, pois o trabalho doméstico remunerado era visto como condição para a libertação das mulheres de classe média dos serviços da casa. No trecho abaixo, retirado do Boletim da Associação Profissional dos Trabalhadores Domésticos do Município do Rio de Janeiro, de 1980, podemos ver essa relação de desconfiança:

Na TV Educativa - Nairjane e Tereza num programa sobre a libertação da mulher deram o seu depoimento sobre o assunto: se a emancipação das patroas é se livrarem do trabalho doméstico, saírem por aí e nos tornarem cada vez mais escravas nas suas casas, então não vemos libertação.

A interação e o intercâmbio com o movimento feminista passou a acontecer de maneira mais intensa e frequente a partir do $5^{\circ}$ Congresso Nacional das Trabalhadoras Domésticas em Recife, quando a ONG feminista SOS Corpo, de Recife, passou a prestar assessoria à realização do congresso e à Associação de Recife, especificamente.

Em escala nacional, o movimento feminista se tornaria um parceiro definitivo das trabalhadoras domésticas na Constituinte, quando encampou o projeto de lei das trabalhadoras domésticas. $\mathrm{O}$ fortalecimento do relacionamento com as entidades feministas ocorreu paralelamente a uma relativa frustração com o movimento sindical, quando este não ofereceu o apoio esperado às trabalhadoras domésticas durante a Constituinte.

$\mathrm{Na}$ Constituição, a gente não teve nenhum apoio da CUT. A CUT não colocou a gente em nenhuma proposta dela. Quem botou a gente foi as feministas. Tinha uma proposta só das empregadas domésticas, mas você tinha quase que ter um percentual de assinaturas, que a gente não conseguiu. (Lenira de Carvalho, membro fundadora da Associação e do Sindicato de Recife). 
O período entre o $5^{\circ}$ Congresso Nacional em Recife, em 1985, e a promulgação da Constituição, em 1988, foi de intensa mobilização entre as trabalhadoras domésticas, com inúmeras visitas ao Congresso Nacional, com o objetivo de pressionar os constituintes a estenderem alguns direitos à categoria.

Após a Constituição, e com a conquista de apenas alguns dos direitos historicamente demandados, a busca do pleno reconhecimento profissional ainda continuou sendo a tônica não mais das Associações, mas dos Sindicatos das Trabalhadoras Domésticas, uma vez que o direito de sindicalização tinha sido conquistado.

\section{Tabela 1}

Adesões às interpretações e articulação política de classe, raça e gênero entre as Associações/Sindicatos das trabalhadoras domésticas

\begin{tabular}{|c|c|c|c|c|c|c|}
\hline $\begin{array}{l}\text { Associação/ } \\
\text { Sindicato }\end{array}$ & 1960 & 1970 & 1980 & 1990 & 2000 & Observações \\
\hline Santos & - & - & - & - & - & $\begin{array}{l}\text { Primeira associação política } \\
\text { da categoria, fundada em } \\
1936 \\
\text { Classe e Raça fortes nas } \\
\text { décadas de } 1930 \text { e } 1940\end{array}$ \\
\hline Campinas & $\begin{array}{l}\text { Classe } \\
\text { Raça }\end{array}$ & - & $\begin{array}{l}\text { Classe } \\
\text { Raça }\end{array}$ & $\begin{array}{l}\text { Classe } \\
\text { Raça } \\
\text { Gênero }\end{array}$ & $\begin{array}{l}\text { Classe } \\
\text { Raça } \\
\text { Gênero }\end{array}$ & $\begin{array}{l}\text { Fundação da Associação: } \\
\text { 18/05/1961 } \\
\text { Atividades interrompidas: } \\
\text { 1968-1979 } \\
\text { Fundação do Sindicato: } \\
\text { 20/11/1988 }\end{array}$ \\
\hline Recife & Classe & Classe & $\begin{array}{l}\text { Classe } \\
\text { Gênero }\end{array}$ & $\begin{array}{l}\text { Classe } \\
\text { Gênero }\end{array}$ & $\begin{array}{l}\text { Classe } \\
\text { Raça } \\
\text { Gênero }\end{array}$ & $\begin{array}{l}\text { Grupo: década de } 1950 \text { e } \\
1960 \\
\text { Fundação da Associação: } \\
1979 \\
\text { Fundação do Sindicato: } 1988 \\
\text { Entre as décadas de } 1960 \text { e } \\
\text { 1980, o discurso classista se } \\
\text { dá a partir da Igreja }\end{array}$ \\
\hline $\begin{array}{l}\text { Rio de } \\
\text { Janeiro }\end{array}$ & Classe & Classe & $\begin{array}{l}\text { Classe } \\
\text { Gênero }\end{array}$ & $\begin{array}{l}\text { Classe } \\
\text { Raça } \\
\text { Gênero }\end{array}$ & $\begin{array}{l}\text { Classe } \\
\text { Raça } \\
\text { Gênero }\end{array}$ & $\begin{array}{l}\text { Fundação da Associação: } \\
\text { 1961/1963 } \\
\text { Fundação do Sindicato: } 1988 \\
\text { Entre as décadas de } 1960 \text { e } \\
\text { 1980, o discurso classista se } \\
\text { dá a partir da Igreja }\end{array}$ \\
\hline Bahia & - & - & $\begin{array}{l}\text { Classe } \\
\text { Raça } \\
\text { Gênero }\end{array}$ & $\begin{array}{l}\text { Classe } \\
\text { Raça } \\
\text { Gênero }\end{array}$ & $\begin{array}{l}\text { Classe } \\
\text { Raça } \\
\text { Gênero }\end{array}$ & $\begin{array}{l}\text { Fundação da Associação: } \\
1986 \\
\text { Fundação do Sindicato: } 1990\end{array}$ \\
\hline
\end{tabular}

Fonte e elaboração: Autor 


\section{Joaze Bernardino Costa}

Tabela 2

Adesão às interpretações e articulação política de classe, raça e gênero
no movimento nacional das trabalhadoras domésticas

\begin{tabular}{|c|c|c|}
\hline $\begin{array}{l}\text { Congressos Nacionais das } \\
\text { Trabalhadoras Domésticas }\end{array}$ & $\begin{array}{l}\text { Intepretações } \\
\text { e articulações }\end{array}$ & Observação \\
\hline $\begin{array}{l}1^{\circ} \text { Congresso Nacional } \\
\text { São Paulo (1968) }\end{array}$ & Classe & $\begin{array}{l}\text { Tema: Demanda dos primeiros direitos } \\
\text { Congresso ainda muito vinculado à Igreja católica }\end{array}$ \\
\hline $\begin{array}{l}2^{\circ} \text { Congresso Nacional } \\
\text { Rio de Janeiro (1974) }\end{array}$ & Classe & $\begin{array}{l}\text { Avaliação dos direitos conquistados em } 1972 \\
\text { Congresso ainda muito vinculado à Igreja católica }\end{array}$ \\
\hline $\begin{array}{l}3^{\circ} \text { Congresso Nacional } \\
\text { Belo Horizonte (1978) }\end{array}$ & Classe & $\begin{array}{l}\text { Tema: Extensão da CLT às trabalhadoras domésticas } \\
\text { Ruptura com o discurso conservador da Igreja católica } \\
\text { Criação informal de uma equipe nacional com o objetivo } \\
\text { de aumentar a interação entre as diversas associações } \\
\text { municipais e estaduais }\end{array}$ \\
\hline $\begin{array}{l}4^{\circ} \text { Congresso Nacional } \\
\text { Porto Alegre (1981) }\end{array}$ & Classe & $\begin{array}{l}\text { Tema: A trabalhadora doméstica menor de idade } \\
\text { Criação formal da Equipe Nacional }{ }^{\star}\end{array}$ \\
\hline $\begin{array}{l}5^{\circ} \text { Congresso Nacional } \\
\text { Recife (1985) }\end{array}$ & $\begin{array}{l}\text { Classe } \\
\text { Gênero }\end{array}$ & $\begin{array}{l}\text { Tema: O reconhecimento da profissão de empregada } \\
\text { doméstica } \\
\text { As intepretações e articulações raciais ainda eram } \\
\text { bastante fracas, embora alguma associações já tivessem } \\
\text { iniciado o diálogo com o movimento negro } \\
\text { Congresso histórico, a partir do qual se iniciou a luta pela } \\
\text { conquista dos direitos constitucionais }\end{array}$ \\
\hline $\begin{array}{l}6^{\circ} \text { Congresso Nacional } \\
\text { Campinas (1989) }\end{array}$ & $\begin{array}{l}\text { Classe } \\
\text { Gênero } \\
\text { Raça }\end{array}$ & $\begin{array}{l}\text { Tema: União, organização, luta } \\
\text { Em 1988, com a promulgação da Constituição, as } \\
\text { trabalhadoras domésticas conquistaram, entre outros, o } \\
\text { direito de fundar Sindicatos } \\
\text { Sobretudo pela ascensão do Sindicato de Campinas, as } \\
\text { interpretações e articulações raciais ganham importância } \\
\text { no movimento nacional } \\
\text { Neste Congresso a Equipe Nacional foi substituída pela } \\
\text { Conselho Nacional^, uma organização mais dinâmica e } \\
\text { efetiva no planejamento nacional do movimento }\end{array}$ \\
\hline $\begin{array}{l}7^{\circ} \text { Congresso Nacional } \\
\text { Rio de Janeiro (1993) }\end{array}$ & $\begin{array}{l}\text { Classe } \\
\text { Gênero } \\
\text { Raça }\end{array}$ & $\begin{array}{l}\text { Tema: O novo perfil da trabalhadora doméstica no Brasil } \\
\text { As intepretações e articulações de classe, raça e gênero se } \\
\text { tornam centrais no movimento das trabalhadoras } \\
\text { domésticas } \\
\text { Em 1997, como um desenvolvimento da Equipe Nacional } \\
\text { e do Conselho Nacional, é fundada a Federação Nacional } \\
\text { das Trabalhadoras Domésticas }\end{array}$ \\
\hline $\begin{array}{l}8^{\circ} \text { Congresso Nacional } \\
\text { Belo Horizonte }(2001)\end{array}$ & $\begin{array}{l}\text { Classe } \\
\text { Gênero } \\
\text { Raça }\end{array}$ & $\begin{array}{l}\text { Tema: Igualdade na luta e equiparação dos direitos } \\
\text { Interpretações e articulações de raça, classe e gênero } \\
\text { fortes } \\
\text { Consolidação do diálogo com organizações internacionais } \\
\text { e multinacionais. Exemplo: Conlactraho, OIT, ONU } \\
\text { Mulheres }\end{array}$ \\
\hline
\end{tabular}

(continua) 


\section{Controle de vida, interseccionalidade e política de empoderamento}

Tabela 2

Adesão às interpretações e articulação política de classe, raça e gênero no movimento nacional das trabalhadoras domésticas (continuação)

\begin{tabular}{lll}
\hline $\begin{array}{l}\text { Congressos Nacionais das } \\
\text { Trabalhadoras Domésticas }\end{array}$ & $\begin{array}{l}\text { Intepretações e } \\
\text { articulações }\end{array}$ & Observação \\
\hline & Classe & $\begin{array}{l}\text { Tema: } 70 \text { anos de luta } \\
\text { Interpretações e articulações de raça, classe e gênero fortes } \\
\text { Consolidação do diálogo com organizações internacionais } \\
\text { e multinacionais }\end{array}$ \\
$\begin{array}{ll}9^{\circ} \text { Congresso Nacional } \\
\text { Salvador (2006) }\end{array}$ & Raça & $\begin{array}{l}\text { Diálogos com governos. Exemplo: Seppir, SPM, } \\
\text { prefeituras }\end{array}$ \\
& & $\begin{array}{l}\text { Tema: A hora é agora: para levantar e fortalcer nossas } \\
\text { bandeiras } \\
\text { Interpretações e articulações de raça, classe e gênero fortes } \\
\text { Consolidação do diálogo com organizações internacionais } \\
\text { e multinacionais } \\
\text { Diálogos com governos. Exemplo: Seppir, SPM, } \\
\text { prefeituras }\end{array}$ \\
\hline
\end{tabular}

^ Tanto a Equipe Nacional quanto o Conselho Nacional foram organizações precursoras da Federação Nacional das Trabalhadoras Domésticas

Fonte e elaboração: Autor

Em escala nacional, o período após a Constituição foi de ascensão do Sindicato de Campinas e, posteriormente, do Sindicato da Bahia, que iniciou as atividades enquanto grupo na década de 1970, consolidando-se efetivamente também no início dos anos de 1980.

Com a conquista de maior espaço nacional dos Sindicatos de Campinas e da Bahia, as interpretações e motivações políticas raciais e feministas ganham mais espaço entre o movimento nacional das trabalhadoras domésticas. Não se trata de dizer que as interpretações classista-sindicais desapareceram ou foram invalidadas, mas de constatar que houve um reposicionamento dos fatores, passando a haver uma maior abertura às interpretações raciais e de gênero. Isso se deveu, em primeiro lugar, ao fato de que historicamente os Sindicatos de Campinas e da Bahia tinham vínculos com o movimento negro. Em segundo lugar, ao diálogo com o movimento feminista iniciado na primeira metade da década de 1980 e fortalecido ao longo daquela década e das seguintes.

De meados dos anos 1990 até o presente momento, o que vemos é a consolidação das alianças entre movimentos negros, movimentos feministas e movimentos classistas. Além da consolidação dessas alianças, percebe-se a construção de uma rede com atores internacionais, governos e organismos, tais como a Confederação Latino-Americana e do Caribe de Trabalhadoras Domésticas (Conlactraho), a Rede Internacional de Trabalhadoras Domésticas (Internatio- 


\section{Joaze Bernardino Costa}

nal Domestic Workers Network, IDWN), a ONU mulheres, a Organização Internacional do Trabalho(OIT), a Secretaria Especial de Promoção de Políticas de Igualdade Racial (Seppir), a Secretaria de Políticas para as Mulheres (SPM) etc. A aprovação, na $100^{\text {a }}$ Conferência Internacional do Trabalho da OIT, da Convenção $\mathrm{n}^{\circ} 189$ e da Recomendação ${ }^{\circ} 201$ sobre Trabalho Decente para as Trabalhadoras e os Trabalhadores Domésticos, no dia 16 de junho de 2011, veio evidenciar essa rede transnacional constituída pelas trabalhadoras domésticas (cf. Goldsmith, 2013).

A aprovação da Convenção ${ }^{\circ} 189$ foi acompanhada por uma delegação brasileira significativa do ponto de vista numérico. Entre governo, empregadores e trabalhadores, mais de 70 pessoas estiveram presentes à Conferência da OIT. Lá estavam cinco trabalhadoras domésticas ${ }^{9}$ e a deputada Benedita da Silva, que se tornaria peça importante para a aprovação da Emenda Constitucional que equiparou as trabalhadoras domésticas aos demais trabalhadores do país.

Como um subproduto da Convenção $\mathrm{n}^{\circ} 189$, que deveria ser ratificada voluntariamente pelos países membros da OIT para ter uma efetiva validade legal, o tema trabalho doméstico foi posto na agenda política brasileira e passou a ocupar a mídia. Assim, em diálogo com as trabalhadoras domésticas, ONGs feministas e antirracistas, sindicatos de outras categorias, organismos internacionais e Secretarias de Estado, um grupo de parlamentares propôs uma Emenda à Constituição Federal, solicitando a alteração do artigo que restringia a aplicação dos direitos sociais e trabalhistas no caso das trabalhadoras domésticas. No último dia 2 de abril de 2013, o Congresso Nacional aprovou por unanimidade o voto da relatora deputada Benedita da Silva e pôs fim a uma segregação legal que estava enraizada na Constituição Federal do Brasil.

Indubitavelmente, tomando o movimento das trabalhadoras domésticas em sua dimensão nacional, em meados da década de 1980 somaram-se às interpretações e demandas classistas as interpretações de gênero, e no final da mesma década somou-se às interpretações e articulações de classe e gênero a dimensão racial. Dessa forma, podemos afirmar que o movimento das trabalhadoras domésticas se constitui num verdadeiro movimento feminista negro.

A fim de sintetizar o que relatamos acima, a Tabela 1 descreve as interpretações e articulações predominantes em cada associação/sindicato ao longo das décadas. Por outro lado, a Tabela 2 descreve as interpretações e articulações predominantes no movimento nacional como um todo. Para descrever o movimento nacional, optamos por destacar os congressos nacionais da categoria profissional, uma vez que estes representam acordos e decisões que transcendem as decisões locais de cada associação/sindicato. 


\section{Controle de vida, interseccionalidade e política de empoderamento}

\section{Considerações finais: as organizações politicas das trabalhadoras domésticas e o controle de suas vidas}

Sabemos que muita água deverá passar por baixo da ponte a fim de que a equiparação legal das trabalhadoras domésticas aos demais trabalhadores se efetive. A conquista da equiparação legal não é o fim da história num país caracterizado pelo descumprimento de leis, haja vista que a legislação que garante a assinatura da carteira de trabalho das trabalhadoras domésticas remonta a 1972 e apenas $26,3 \%$ delas têm suas carteiras assinadas. Todavia, o significativo nessa longa trajetória não é simplesmente o registro da história na perspectiva de vencedores e perdedores, e sim o reconhecimento de protagonistas que comumente são olvidadas.

Ao longo dos quase 80 anos de existência do movimento organizado das trabalhadoras domésticas no Brasil constatamos a heterogeneidade de seu ativismo. Tomando como referência o tronco histórico do movimento - os sindicatos de Campinas, São Paulo, Rio de Janeiro, Bahia e Recife -, percebemos que o envolvimento desses sindicatos com as interpretações e com as articulação políticas de classe, raça e gênero varia espacial e temporalmente.

Especialmente até meados da década de 1980, praticamente todos as associações privilegiavam as interpretações de classe, à exceção das associações de Campinas e Bahia, que já possuíam interpretações e articulações raciais. Em meados da década de 1980 , no $5^{\circ}$ Congresso Nacional da categoria, as interpretações de gênero ganharam espaço nacionalmente, em decorrência do diálogo entre as trabalhadoras domésticas e o movimento feminista. Todavia, as tensões entre o movimento das trabalhadoras domésticas e o movimento feminista foram mantidas, devido às diferenças e às desigualdades de classes. Somente na segunda metade da década de 1980, com a ascensão no movimento nacional dos sindicatos de Campinas e Bahia, foi que as interpretações e articulações raciais ganharam importância, somando-se às já existentes interpretações e articulações de raça e gênero. Sobretudo após a década de 1990, o movimento das trabalhadoras domésticas começou a ter uma articulação internacional, passando a compor sua rede de articulação não somente com movimentos sociais, mas também com órgãos multilaterais e governos.

Ao longo de todo esse percurso histórico que descrevemos, percebemos uma associação entre esses três eixos de poder - raça, classe e gênero - e a política de empoderamento das trabalhadoras domésticas. Em outras palavras, a interseccionalidade construída pelo movimento das trabalhadoras domésticas entre os eixos de poder raça, classe e gênero permitiu o fortalecimento de suas interpretações de demandas democráticas e a construção da solidariedade política com outros movimentos. Registrar esta história não é só registrar a história da luta pelo controle da própria vida, mas é também o esforço de registrar uma história do ponto de vista das atrizes subalternas, conferindo-lhes o protagonismo que lhes cabe. 
1. Existem aproximadamente 40 sindicatos de trabalhadoras domésticas no Brasil. Além dos pesquisados, destacam-se em importância histórica, devido à atuação política, os sindicatos de Belo Horizonte e Porto Alegre, que já organizaram três congressos nacionais, e os sindicatos do Maranhão, de Belém do Pará e de Nova Iguaçu, devido a importantes atuações políticas na atualidade.

2. As trabalhadoras domésticas já realizaram dez congressos nacionais: $1^{\circ}$ Congresso Nacional, em São Paulo, 1968; $2^{\circ}$ Congresso Nacional, no Rio de Janeiro, 1974; $3^{\circ}$ Congresso Nacional, em Belo Horizonte, 1978; $4^{\circ}$ Congresso Nacional, em Porto Alegre, 1981; $5^{\circ}$ Congresso Nacional, em Recife, $1985 ; 6^{\circ}$ Congresso Nacional, em Campinas, $1989 ; 7^{\circ}$ Congresso Nacional, no Rio de Janeiro, 1993; $8^{\circ}$ Congresso Nacional, em Belo Horizonte, 2001; $9^{\circ}$ Congresso Nacional, em Salvador, 2006; $10^{\circ}$ Congresso Nacional, em Recife, 2011.

3. O termo "empregado/a doméstico/a" só foi utilizado quando se tratou de pessoa jurídica. As trabalhadoras domésticas a partir da década de 1980 deliberaram a substituição do termo por "trabalhadora doméstica" a fim de fortalecer a luta pelo enquadramento trabalhista da categoria.

4. A Consolidação das Leis do Trabalho, no seu artigo $7^{\circ}$, dizia o seguinte: "Os preceitos constantes da presente Consolidação, salvo quando for, em cada caso, expressamente determinado em contrário, não se aplicam: (a) aos empregados domésticos, assim considerados, de um modo geral, os que prestam serviços de natureza não econômica a pessoa ou a família, no âmbito residencial destas".

5. A JOC foi um braço da Ação Católica Operária, movimento da Igreja católica fundado pelo padre belga José Cardijn (1882-1967), que consistiu na mobilização de leigos que respondiam ao apelo do Papa Pio XI (Encíclica Urbano Dei, 1922) para que dessem um testemunho de sua fé no meio em que viviam (cf. Soares, 2002).

6. Durante uma das pesquisas, foram entrevistadas 26 trabalhadoras filiadas à Fenatrad e aos seguintes sindicatos: Sindicato do Rio de Janeiro, Campinas, São Paulo, Recife, Bahia. Todas as entrevistadas autorizaram-me a citar seus nomes reais, quando a citação se referisse ao histórico da organização política das trabalhadoras domésticas (cf. Bernardino-Costa, 2007).

7. "Santa Zita nasceu em 1218 em Monsagrati, nos arredores da cidade de Lucca. Filha de camponeses, aos 12 anos foi trabalhar como empregada doméstica na casa de uma rica família. Perguntava-se sempre a si mesma: 'Isto agrada ao Senhor?' ou 'Isto desagrada a Jesus?' Foi-lhe confiado o encargo de distribuir esmolas cada sextafeira. E dava do seu pouco, da sua comida, das suas roupas, daquilo que possuía, das parcas economias. Dizem que um dia foi surpreendida enquanto socorria os necessitados. No seu avental o que era alimento se converteu em flores. Foi doméstica a vida toda. Na hora da morte tinha ajoelhada a seus pés toda a família Fatinelli, a quem servira toda vida. Morreu no dia 27 de abril de 1278. Pio XII a proclamou padroeira das empregadas domésticas do mundo inteiro." (http//www.chatcristao.hpg. ig.com.br/santa_zita.htm)

8. Cabe destacar que estamos falando do predomínio da discussão classista no movimento em sua dimensão nacional. É claro, como dissemos anteriormente, que já havia a interpretação racial por parte da Associação de Campinas, porém essa dimensão da interpretação e da luta polí- 


\section{Controle de vida, interseccionalidade e política de empoderamento}

tica ainda não tinha alcançado um reconhecimento nacional.

9. As cinco trabalhadoras domésticas que estiveram presentes à $100^{a}$ Conferência Internacional do Trabalho foram: Creuza Maria de Oliveira (presidente da Federação Nacional de Trabalhadoras Domésticas), Sueli Maria de Fátima Santos (Sin-

\section{Referências bibliográficas}

ÁVILA, Maria Betânia de Melo. O tempo do trabalho das trabalhadoras domésticas: tensões entre dominação/exploração e resistência. Recife: Editora Universitária da UFPE, 2009.

BERNARDINO-COSTA, Joaze. Colonialidade do poder e subalternidade: os sindicatos das trabalhadoras domésticas no Brasil. Tese (Doutorado em Sociologia). Brasília: Universidade de Brasília, 2007.

Trabalhadoras domésticas no Distrito Federal e suas condições de trabalho. In: MORI, Natalia et alii. Tensões e experiências: um retrato das trabalhadoras domésticas de Brasília e Salvador. Brasília: Centro Feminista de Estudos e Assessoria, 2011.

BRAH, Avtar. Cartographies of diaspora: contesting identities. London/New York: Routledge, 1996.

Diferença, diversidade e diferenciação. Cadernos Pagu 26, 2006, p. 329-376.

BRITES, Jurema. Afeto, desigualdade e rebeldia: bastidores do serviço doméstico. Tese (Doutorado em Antropologia). Porto Alegre: Universidade Federal do Rio Grande do Sul, 2000. dicato das Trabalhadoras Domésticas de Sergipe), Maria Noeli dos Santos (Sindicato das Trabalhadoras Domésticas do Município do Rio de Janeiro), Maria Regina Teodoro (Sindicato das Trabalhadoras Domésticas de Campinas) e Ione Santana de Oliveira (Sindicato das Trabalhadoras Domésticas do Estado da Bahia).

COLLINS, Patricia Hill. Black feminist thought: knowledge, consciousness, and the politics of empowerment. New York and London: Routledge, 2000.

CRENSHAW, Kimberlé. Documento para o Encontro de Especialistas em Aspectos da Discriminação Racial Relativos ao Gênero. Revista Estudos Feministas 10 (1), 2002, p. 171-188.

Mapping the margins: intersectionality, identity politics, and violence against women of color. In: ALCOFF, Linda Martín and MENDIETA, Eduardo (eds). Identities: race, class, gender, and nationality. Malden/Oxford/Carlton: Black-well Publishing, 2006, p. 175-200.

FOUCAULT, Michel. O sujeito e o poder. In: DREYFUS, Hubert e RABINOW, Paul (eds.). Michel Foucault: uma trajetória filosófica para além do estruturalismo e da hermenêutica. Rio de Janeiro: Forense Universitária, 1995, p. 231-249.

GIACOMINI, Sonia Maria. Mulatas profissionais: raça, gênero e ocupação. Revista Estudos Feministas 14 (1), 2006, p. 85-101.

GOLDSMITH, Mary. Los espacios internacionales de la participación política de las trabajadoras remuneradas del hogar. 
Joaze Bernardino Costa

Revista de Estudios Sociales 45, 2013, p. 233-246.

GONZALES, Lélia. Racismo e sexismo na cultura brasileira. Revista Ciências Sociais Hoje 2, 1984, p. 223-244.

GRAHAN, Sandra Lauderdale. Proteção e obediência: criadas e seus patrões no Rio de faneiro (1860-1910). São Paulo: Companhia das Letras, 1992.

GUHA, Ranajit (ed.) A subaltern studies reader (1986-1996). Minneapolis: University of Minnisota Press, 1997.

HOOKS, Bell. Intelectuais negras. Estudos Feministas, v. 3, n. 2, 1995, p. 464-469.

KARASH, Mary. $A$ vida do escravo no Rio de Faneiro (1808-1850). São Paulo: Companhia das Letras, 2000.

KOFES, Maria Suely. Mulher, mulheres: identidade, diferença e desigualdades na relação entre patroas e empregadas domésticas. Campinas: Editora da Unicamp, 2001.

MATTOSO, Kátia. Ser escravo no Brasil. São Paulo: Editora Brasiliense, 2003.
NASCIMENTO, Abdias. Quilombo: vida, problemas e aspirações do negro (1948-1950). São Paulo: Editora 34, 2003.

PINHEIRO, Luana Simões; FONTOURA, Natália; PEDROSA, Claudia. Situação atual das trabalhadoras domésticas no país. In: MORI, Natália et alii. Tensões e experiências: um retrato das trabalhadoras domésticas de Brasília e Salvador. Brasília: Centro Feminista de Estudos e Assessoria, 2011.p. 33-68.

PINTO, Elisabete Aparecida. Etnicidade, gênero e trajetória de vida de Dona Laudelina de Campos Melo (1904-1991). Dissertação (Mestrado em Educação), Universidade de Campinas, Brasil, 1993.

RIVERA CUSICANQUI, Silvia; BARRAGÁN, Rossana (eds.). Debates post-coloniales: una introducción a los estudios de la subalternidad. La Paz: Sephis/Aruwiyri, 1997.

SERMOG, Ele; NASCIMENTO, Abdias. Abdias Nascimento: o Griot e as muralhas. Rio de Janeiro: Pallas, 2006.

SOARES, Odete de Azevedo. Uma história de desafios: FOC no Brasil - 1935/1985. Rio de Janeiro: sem editora, 2002.

\section{Resumo}

Motivado pelas recentes discussões legais em torno do trabalho doméstico no Brasil, este artigo propõe-se destacar o protagonismo das organizações políticas das trabalhadoras domésticas na conquista dos direitos da categoria profissional. Baseado em entrevistas realizadas com trabalhadoras domésticas sindicalizadas em diversas cidades brasileiras, o artigo estrutura seu argumento a partir do conceito de interseccionalidade, demonstrando como, ao longo dos últimos 80 anos, as organizações políticas dessas trabalhadoras têm se articulado com o movimento classista-sindical, negro e feminista, o que tem sido fundamental para desenvolver uma política de empoderamento e de autocontrole da vida.

Palavras-chave: sindicato das trabalhadoras domésticas; interseccionalidade; empoderamento; raça; classe; gênero. 


\begin{abstract}
Motivated by the recent legal discussions about domestic workers in Brazil, this paper aims to highlight the leading role of domestic workers' political organizations in the conquest of rights. Based on interviews with unionized domestic workers in different Brazilian cities, the article uses the concept of interseccionality and shows how, in the last 80 years, domestic workers' political organizations have articulated themselves with trade unions, as well as black and feminist movements, and how this articulation is important for a politics of empowerment and control of their own lives.

Key words: female domestic workers' unions; interseccionality; politics of empowerment; race; class and gender.

Résumé

Motivé par les récentes discussions légales sur le travail domestique au Brésil, cet article veut mettre en relief le protagonisme des organisations politiques des employées domestiques dans la conquête des droits de leur catégorie professionnelle. Appuyé sur des interviews avec des employées domestiques syndiquées dans différentes villes brésiliennes, l'article organise son argumentation à partir du concept d'interseccionalité, montrant comment, au long des derniers 80 ans, les organisations politiques de ces ouvrières se sont articulées avec les mouvements classiste, des noirs et féministe, ce qui a été fondamental pour qu'elles puissent développer une politique d'autonomisation et d'autocontrôle de leur vie.
\end{abstract}

Mots-clés: syndicat des employées domestiques; interseccionalité; autonomisation; race; classe; genre. 